\title{
DISTRIBUIÇÃO SAZONAL DAS LARVAS DE Mylossoma aureum E $M$. duriventre (OSTEICHTHYES: SERRASALMIDAE) NA COSTA DO CATALÃO, RIO AMAZONAS, AMAZONAS, BRASIL
}

\author{
Edinbergh Caldas de OLIVEIRA*
}

RESUMO - A distribuição sazonal das larvas de Mylossoma aureum e $M$. duriventre (Osteichthyes: Serrasalmidae), foi estudada na costa do Catalão, rio Amazonas durante três anos. As larvas de ambas espécies de Mylossoma foram mais abundantes na estação marginal do que na estação localizada no centro do rio. O periodo de ocorrência das duas espécies foi semelhante e durou em média 109 dias, variando de novembro-janeiro a abril-maio. A variação na abundância de larvas durante o período de ocorrência não se relacionou com a luminosidade da lua, nem com a pluviosidade local. Porém, a enchente apresentou efeito na variação da densidade de larvas de $M$. aureum no ano de 1994-1995.

Palavras-chave: Amazônia, peixe, larva, distribuição sazonal, Characiformes.

Seazonal Larval Distribution of the Mylossoma aureum and $M$. duriventre (Osteichthyes: Serrasalmidae) on the Coast of Catalão in the Amazon River, Amazonas State, Brazil

\begin{abstract}
The seazonal variation of larval distribution of Mylossoma aureum and M. duriventre (Osteichthyes: Serrasalmidae), were studied in the coast of Catalão, Amazon River during three years. Only the first feeding stage larvae were found drifting on the river. Larvae were more abundant near the banks than in the middle river channel. The average larval drift lasted 109 days, varying from November-January to April-May. The variation of larval abundance was not related to the rain or the moon phases, but only to an increase of water level for M. aureum in year of 1994-1995.
\end{abstract}

Key-words: Amazon, fish, larvae, seazonal distribution, Characiformes.

\section{INTRODUÇÃO}

Muitos peixes tropicais de água doce e do mar possuem extensas desovas sazonais com diferentes individuos em maturação em diferentes épocas do ano. Nenhuma dessas no entanto, são regulares retornando aos periodos de intensa atividade de desova (Bye, 1984). Outras espécies, incluindo muitas tropicais de água doce têm restritos periodos de desova (LoweMcConnell, 1979).

Através da variação sazonal na abundância de larvas presentes no rio, é possivel se avaliar a época e a intensidade de desova de peixes da Amazônia. As larvas de
Characiformes estão presentes no rio Amazonas por um período de 10 meses. Porém, sua abundância é concentrada em poucos meses, que coincidem com o início da enchente e com o periodo de desova de várias espécies do grupo (Araujo-Lima \& Oliveira, 1998). A sobreposição entre o periodo de deriva e a enchente é importante para o transporte das larvas. O início da época de desova deste grupo tem sido relacionada a diversos fatores ambientais. $\mathrm{O}$ aumento no nivel do rio causado pela enchente é o fator mais citado pela literatura, mas a chuva e, em menor escala as fases da lua, são frequentemente mencionados (Schwassmann, 1978;

•Lab. de Zoologia/ICB. Universidade do Amazonas, Manaus, AM. Brasil 69077-000, eoliveira@fua.br 
Goulding, 1980; Ribeiro, 1983; LoweMCconnell, 1987; Fernandes, 1997). Apesar de algumas informações sobre a sazonalidade da reprodução dos Characiformes do rio Amazonas, pouco se sabe sobre as variações interanuais na desova das espécies deste grupo e sobre a influência dos parâmetros ambientais (Vazzoler \& Menezes, 1992).

Este estudo abordou a influência da enchente na distribuição sazonal das larvas de Mylossoma aureum (Spix, 1829) e Mylossoma duriventre (Cuvier, 1817). Esta distribuição foi estudada comparando coletas realizadas durante três anos. As variações na abundância larval, ou seja na intensidade de deriva, foram também testadas em relação a outros fatores ambientais como: luminosidade da lua e precipitação.

As espécies estudadas, $M$. aureum e $M$. duriventre, representam uma parte importante da pesca comercial na Amazônia Central (Petrere Jr., 1985; Batista, 1998), contribuindo com cerca de $7-13 \%$ do pescado desembarcado em Manaus (Merona \& Bittencourt, 1988), oscilando entre o $2^{\circ}$ e $6^{\circ}$ itens da produção pesqueira desembarcada nos municipios de Manacapuru, Manaus, Itacoatiara e Parintins (Batista, 1998). Estas espécies têm ampla distribuição geográfica ocorrendo nas bacias Amazônica e do Orinoco (MachadoAllison \& Castillo, 1992). As larvas destas espécies são abundantes no rio e podem ser identificadas com segurança (Araujo-Lima et al., 1993).

A variação interanual no aparecimento das larvas no rio é uma ferramenta útil para se determinar a época de desova destas espécies, o que constitui um dos aspectos de maior importância para a legislação pesqueira, imprescindivel para o manejo da pesca e conservação dos recursos naturais da Amazônia.

\section{MATERIAL E MÉTODOS}

\section{Obtenção das amostras}

Foram amostradas duas estações nos periodos de agosto de 1981 a julho de 1982; novembro de 1984 a maio de 1985 e; dezembro de 1994 a dezembro de 1995. As amostras coletadas antes de 1994 estavam preservadas em formalina a $10 \%$ no Laboratório de Ecologia de Peixes II / CPBA / INPA. $\mathrm{O}$ procedimento de amostragem foi semelhante em todos os anos. A estação 1, na Costa do Catalão (5-10 $\mathrm{m}$ da margem) e a estação 2 no meio do rio Amazonas (Fig. 1), foram amostradas na superfície da água ( 30 cm) semanalmente em 1981-1982 e quinzenalmente nos outros anos. Foi utilizada uma rede cônico-cilindrica de boca quadrangular com $0,046 \mathrm{~m}^{2}$ de área, $3,25 \mathrm{~m}$ de comprimento e 0,465 $\mathrm{mm}$ de malha. O horário de coleta e $\mathrm{o}$ volume filtrado seguiram os padrões de Oliveira \& Araujo Lima (1998) e as larvas identificadas segundo Araujo Lima et al. (1993).

\section{Análise das amostras}

A variação sazonal na 


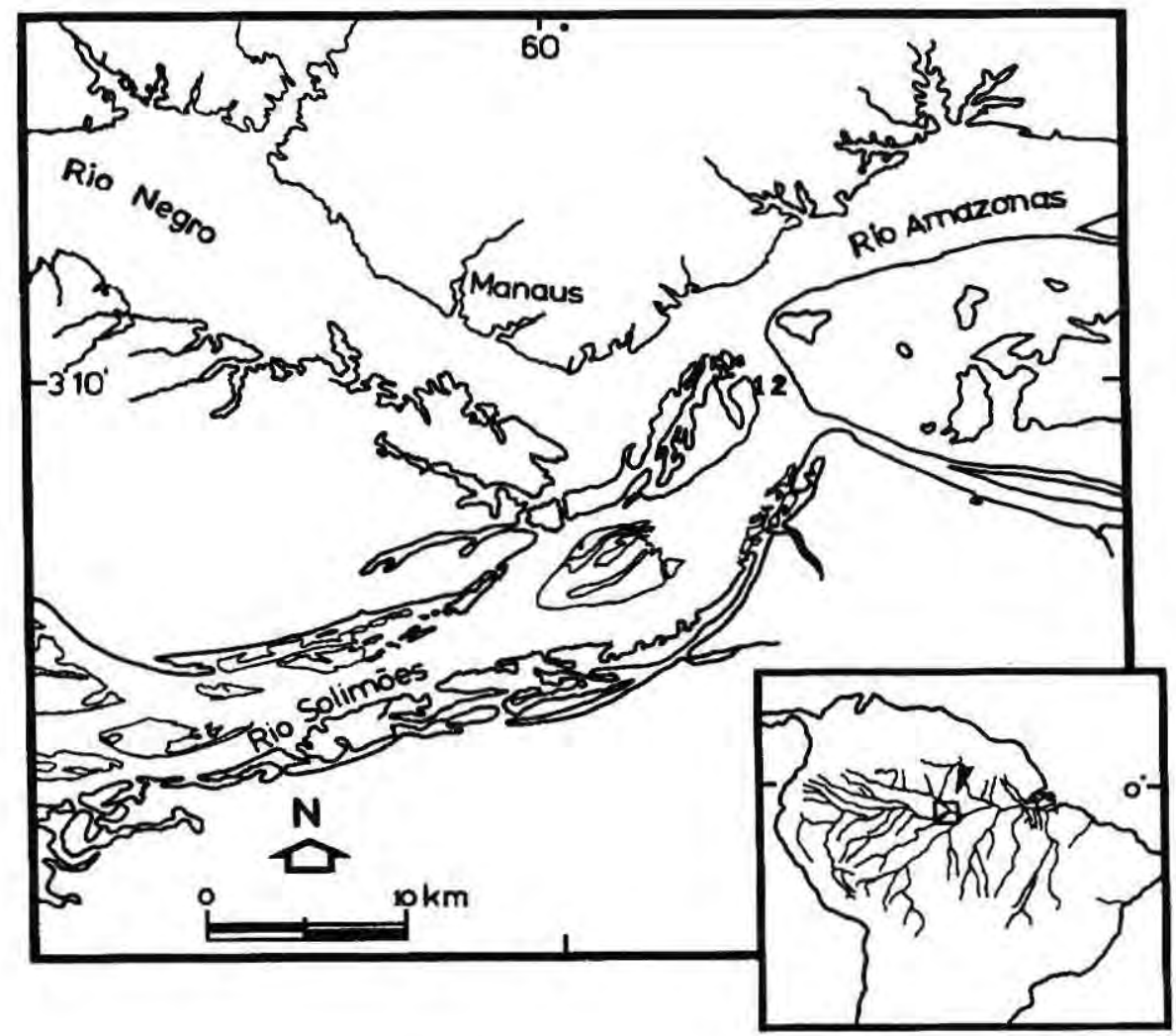

Figura 1. Área de estudo e estações de coleta. As estações usadas para o estudo da sazonalidade estão representadas como: $1=$ costa do Catalão e $2=$ centro do rio Amazonas.

abundância de larvas de $M$. aureum e $M$. duriventre foi analisada através do material coletado na estação 1 , cuja abundância de larvas foi maior. Para avaliarmos o efeito da enchente, chuva e luminosidade da lua na variação sazonal da abundância de larvas, foi usada uma regressão múltipla (Zar, 1984), ajustada em função do dia das coletas, considerando como dia 1, o pico na densidade de larvas. Para testar a relação entre estas variáveis e a variação na abundância de larvas considerando o efeito das possíveis desovas que poderiam ter ocorrido há 4 ou 8 dias anteriores a coleta (em função da provável idade das larvas utilizadas neste estudo, estimada entre 4 e 8 dias), foi adotado o procedimento de se utilizar o valor acumulado de 0 a 4 , de 4 a 8 e de 8 a 12 dias anteriores ao dia de coleta. A variável enchente, foi considerada como a subida do nível do rio no dia da coleta e o seu valor acumulado (dados da Portobrás, Manaus). A variável chuva, seguiu a mesma metodologia (dados da EMBRAPA, Manaus). Os dados das fases 
da lua foram obtidos através do programa de computador ALMANAC (lua nova é igual a 0 e lua cheia igual a 1).

\section{RESULTADOS}

Foram encontradas larvas de $M$. aureum e $M$. duriventre apenas no estádio de primeira alimentação exógena. As larvas apresentaram olho pigmentado, boca formada ou em processo final de formação, saco vitelinico vestigial ou ausente, melanóforos ao longo do corpo, nadadeiras medianas bem desenvolvidas e nadadeiras peitorais pouco desenvolvidas. Todas as larvas coletadas apresentaram comprimento padrão entre 4,1 e $6,8 \mathrm{~mm}$. Cerca de $99,8 \%$ do total das larvas de $M$. aureum e $M$. duriventre foram capturadas na margem (estação 1), e apenas $0,2 \%$ no centro do rio (estação 2). Conseqüentemente a análise da variação sazonal na abundância de larvas foi baseada apenas na estação marginal.

Larvas de $M$. aureum ocorreram no rio de dezembro a abril no ano de 1981-1982, de fevereiro a abril no ano de 1984-1985, e de novembro a abril no ano de 1994-1995 (Fig. 2), totalizando 627 larvas capturadas na estação 1 e 2 . As larvas de $M$. duriventre ocorreram de dezembro a maio no ano de 1981-1982, de janeiro a maio no ano de 1984-1985, e de novembro a maio no ano de 1994 1995 (Fig. 3) somando 4.726 larvas em ambas as estações. As diferenças na duração da deriva em número de dias entre as duas espécies de Mylossoma não foram aparentes nestes três anos. A duração média para ambas espécies foi de 109 dias (desvio padrão $=21$ dias). Os picos de abundância de larvas variaram entre anos (Figs. 2 e 3 ).

$\mathrm{O}$ aparecimento de larvas no rio durante os três periodos analisados ocorreu aproximadamente entre duas semanas a três meses de enchente, com 0,7 a $4,3 \mathrm{~m}$ acima do nível mínimo do rio para ambas espécies de Mylossoma (Figs. 2 e 3). A lua no dia da coleta e no quarto e oitavo dias anteriores, juntamente com a chuva do dia e a acumulada de 4,8 e 12 dias anteriores a coleta, não tiveram efeito significativo sob a variação da densidade de $M$. duriventre e de $M$. aureum derivando nas margens do rio nos anos de 1981-1982 e 1994-1995 (estação 1). Por outro lado, a variação na densidade de larvas de $M$. aureum foi significativamente correlacionada com a enchente acumulada de 4 a 8 dias anteriores a coleta no ano de 1994-1995 (ANOVA; N=10; GL=7; $\mathrm{F}=23,92 ; \mathrm{p}=0,001)$. Esta relação pode ser observada quando se plota os resíduos da abundância de $M$. aureum contra as taxas de aumento na cota do rio (Fig. 4). A densidade de larvas de M. aureum aumentou com o aumento na cota do rio em 1994-1995. O mesmo efeito não foi observado nos anos de 1981-1982, 1984-1985 e, em nenhum dos anos estudados para $M$. duriventre.

\section{DISCUSSÃO}

Durante os três anos estudados, as larvas de $M$. aureum e $M$. duriventre se concentraram nas 


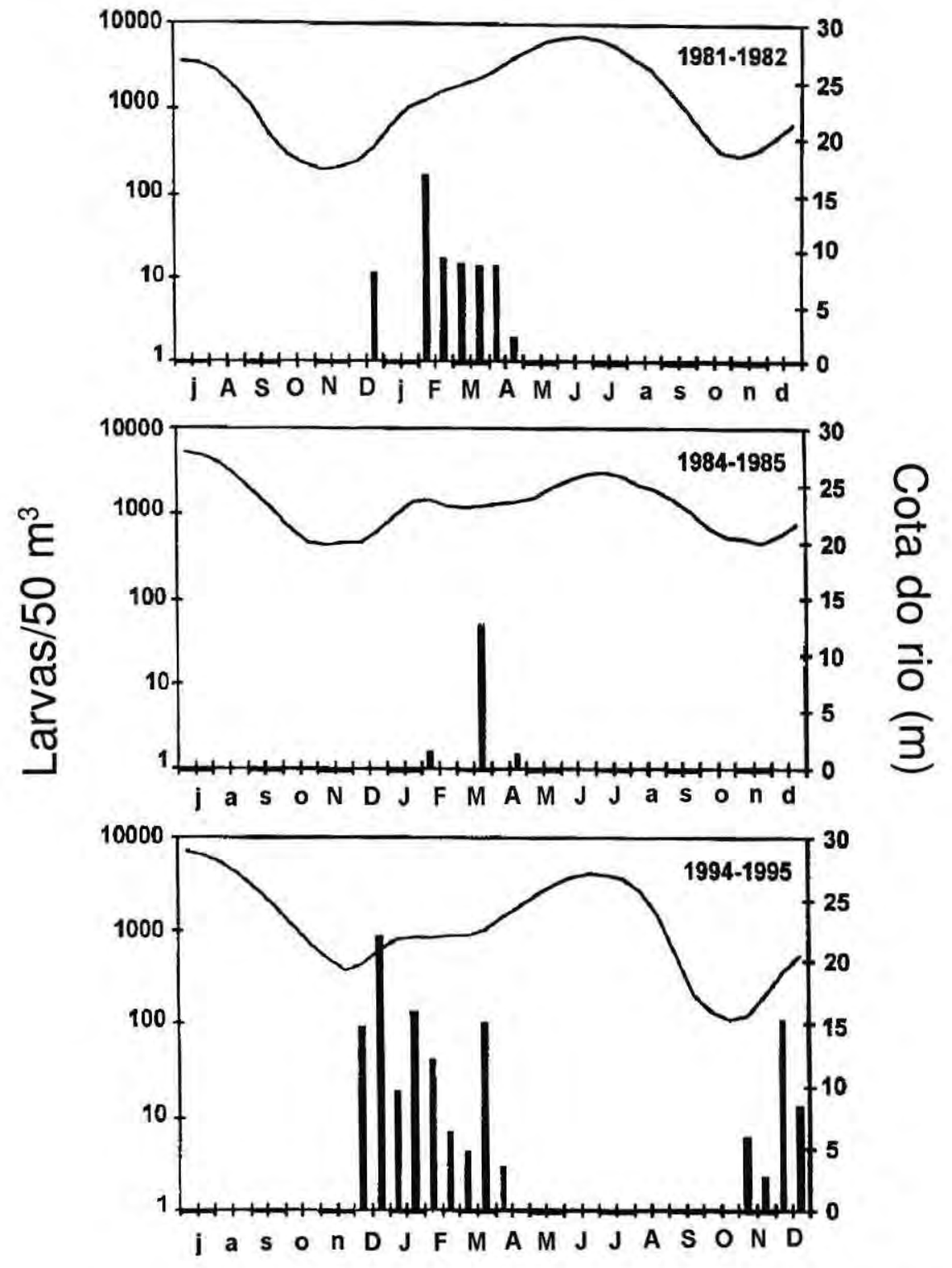

Figura 2. Variação sazonal na densidade de larvas de Mylossoma aureum e na cota do rio (m) durante 1981-1982, 1984-1985 e 1994-1995, na margem do rio (estação 1). As amostras semanais do ano de 1981-1982, foram transformadas em médias quinzenais. As letras menores em itálico correspondem aos meses em que não houveram coletas. 


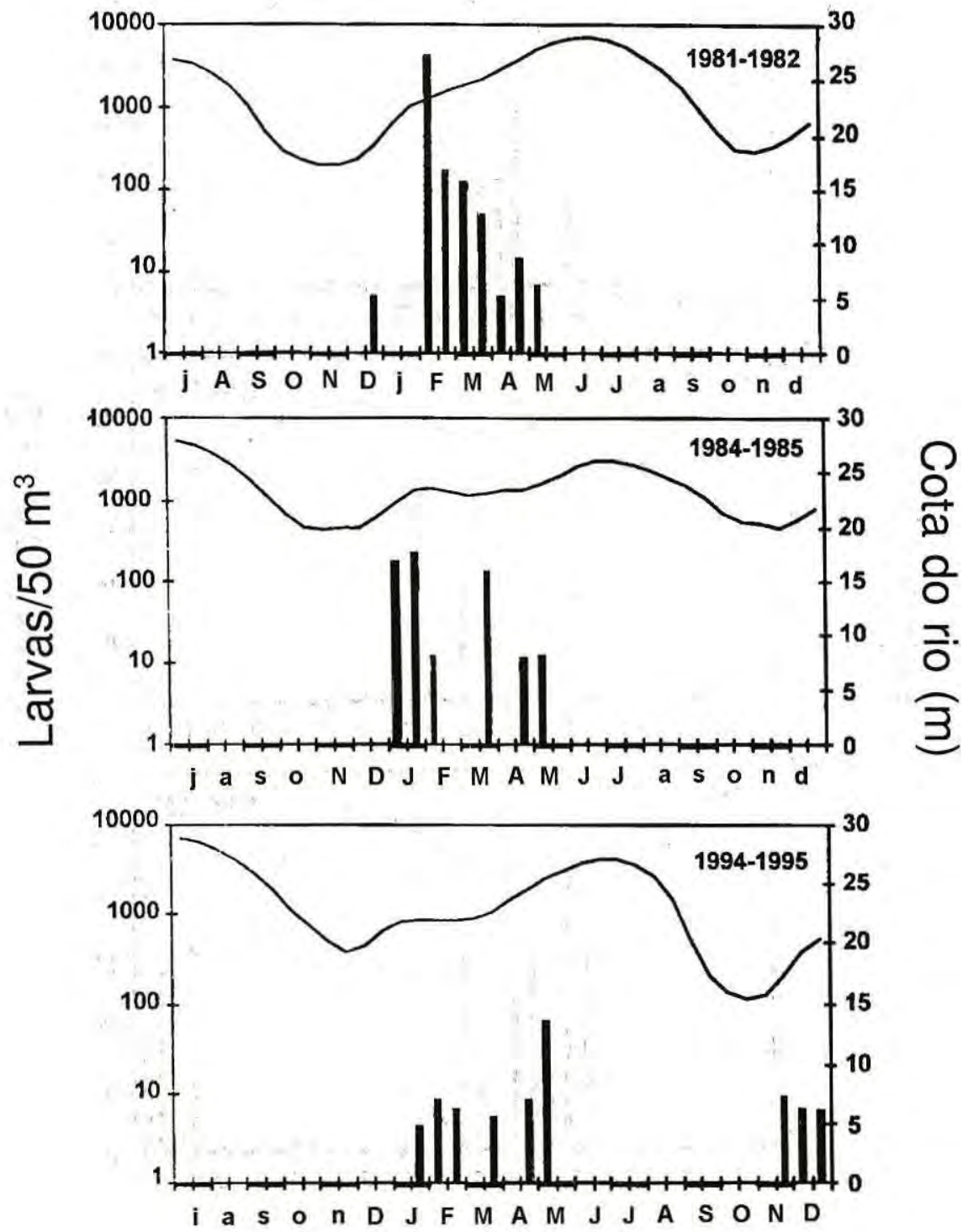

Figura 3. Variação sazonal na densidade de larvas de Mylossoma duriventre e na cota do rio (m) durante 1982-1982, 1984-1985 e 1994-1995, na margem do rio (estação 1). As amostras semanais do ano de 1981-1982, foram transformadas em médias quinzenais. As letras menores em itálico correspondem aos meses em que não houveram coletas. 


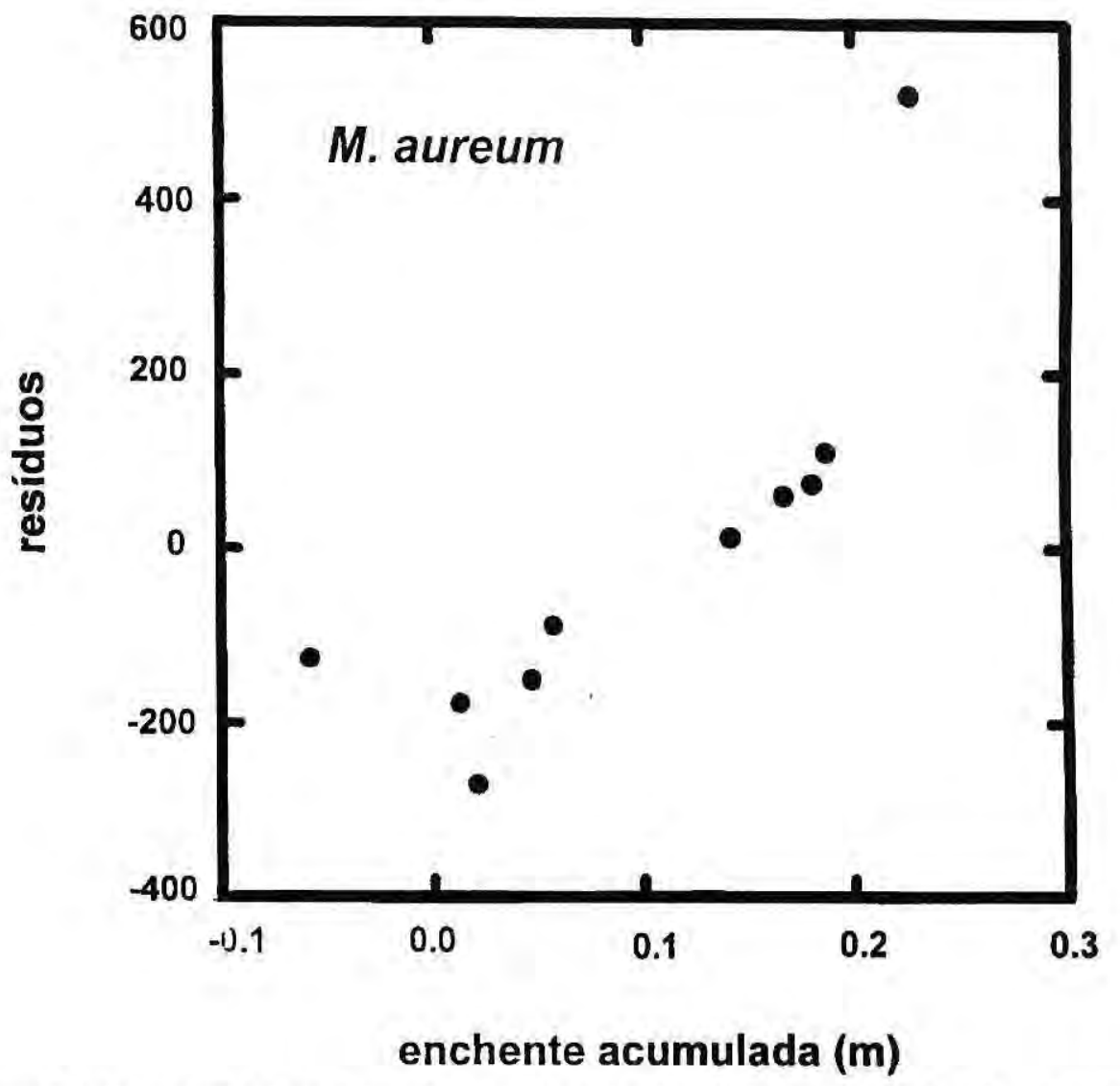

Figura 4. Distribuição dos resíduos da regressão entre densidade de larvas e dias de coleta em relação a enchente acumulada $(\mathrm{m})$ entre 4 e 8 dias anteriores ao dia da coleta, para Mylossoma aureum em 1994-1995.

margens do rio Amazonas e, a densidade no centro do rio foi sempre muito baixa. No entanto, a análise da distribuição sazonal foi baseada em amostras obtidas na superfície e apenas na estação 1 , os resultados podem ter sido influenciados pelas características intrinsecas da estação de coleta e do estrato amostrado. Porém, esta estação está localizada próxima a foz do canal do lago do Catalão, e apresenta densidades de larvas equivalentes às das outras estações utilizadas nos trabalhos de Oliveira \&
Araujo Lima (1998) e Araujo Lima \& Oliveira (1998). Portanto, os resultados sobre a amplitude da distribuição sazonal não parecem ter sido viciados. $\mathrm{O}$ horário de amostragem, também pode ter causado diferenças na abundância das larvas. Entretanto, não afetou a análise sazonal das variações interanuais, principal objetivo do trabalho.

$O$ período de ocorrência de larvas de ambas espécies de Mylossoma durou em média 109 dias. O início da deriva variou entre novembro e 
fevereiro, mas o final ocorreu sempre no final de abril para $M$. aureum e início de maio para $M$. duriventre. $\mathrm{O}$ período de enchente nos três anos compreendeu, em média 229 dias, consequentemente, o início da desova das duas espécies de Mylossoma, ocorreu entre 6,5 e $23 \%$ da enchente total em dias ou 16 a $49 \%$ da enchente total em metros. Estes resultados sugerem que o período de desova dessas espécies sofre forte influência ambiental e está completo antes da metade da enchente

O início da temporada de desova das espécies de rios tropicais geralmente está associado à época das chuvas ou enchentes anuais (LoweMcConnell, 1979 ,

1987; Schwassmann, 1978; Welcomme, 1985; Wootton, 1990). Nikolski (1978) relatou que o calendário dos períodos de desova envolve uma adaptação ligada primariamente à provisão de alimento aos jovens. Lowe-McConnell (1987) ampliou a hipótese quando considera que a seleção natural determina a reprodução nas épocas onde a sobrevivência da prole é favorecida, não apenas por provisão de alimentos adequada, mas também por redução de predação. Um dos benefícios proporcionados com a desova de $M$, aureum e $M$. duriventre estar completa, antes da metade da enchente, parece ser a maximização da temporada de crescimento na planície alagada. Este ambinte que se dilata, fornecerá novos abrigos e reduzirá o efeito dos procssos dependentes de densidade com competição e predação. A expansão da várzea também aumenta a quantidade de matéria orgânica no sistea, através da submersão e decomposição da vegetação marginal (Junk et al., 1983). A relação entre a inundação e o fornecimento de alimentos para as larvas de Mylossoma, ainda é desconhecida, pois não existem dados sobre a dieta das larvas destas espécies.

A enchente influiu diretamente na variação da densidade de larvas de M. aureum no ano de 1994-1995. Esta correlação observada entre a variação na densidade larval e a enchente acumulada de 4 a 8 dias para $M$. aureum, reflete uma provável desova ocorrida antes da captura. O estado de desenvolvimento destas larvas indica que elas eclodiram pelo menos 4 dias antes da captura (Kossovski, 1980; Araujo-Lima, 1994). Portanto, nesse caso, o maior transporte de larvas não parece estar relacionado ao aumento no nivel do rio, mas sugere que esta correlação é principalmente consequência das atividades de desova desta espécie.

Aparentemente, o efeito da enchente atuou de forma pouco acentuada na densidade de larvas de M. duriventre em 1994-1995 e nos demais anos para ambas espécies de Mylossoma. Considerando o reduzido número de estações de coleta neste trabalho, é provável que esta ausência de correlação entre a densidade larval e a enchente para estas espécies nestes anos, pode ter sido devido à grande variação temporal e dinâmica 
temporária da concentração de larvas distribuídas em enormes distâncias ao longo das margens do rio Amazonas e em diferentes microhabitats. O que não descarta a importância decisiva da enchente como principal disparador das desovas para ambas espécies de Mylossoma, demonstrada pela presença de larvas no rio em periodos característicos para cada espécie e até cerca da metade da enchente nos meses de abril e maio nos três anos analisados.

A variação na densidade de larvas durante o período de ocorrência foi independente das chuvas e das fases da lua. A pluviosidade local e luminosidade da lua não apresentaram um efeito mensurável na variação da densidade de larvas para nenhuma das espécies de Mylossoma. Goulding (1980) e Werder \& Soares (1984) relacionaram a desova de Characiformes na Amazônia, à subida do nível do rio acompanhada por forte precipitação. Outros autores (Ihering \& Azevedo, 1934; Godoy, 1959) relacionaram desova às chuvas em áreas onde estas causam aumento de subida no nível do rio. Boehlert \& Mundy (1988) relataram que os ritmos endógenos em peixes podem ter periodicidade lunar. Porém, no rio Amazonas tal influência não é clara, e no caso da chuva, a comparação não é precisa, devido as chuvas serem altamente regionalizadas (Werder, 1983). Portanto, este aspecto poderia explicar a ausência de correlação entre as chuvas e a variação na densidade de larvas de $M$. aureum e
M. duriventre. Existe também a possibilidade de que as chuvas e as fases da lua não exerçam influências importantes nas desovas ou transporte de larvas destas espécies e atuem mais diretamente nos movimentos migratórios para reprodução (Bayley, 1973; Ribeiro, 1983; Welcomme, 1985; Fernandes, 1997).

Outros fatores abióticos como condutividade, $\mathrm{pH}$, oxigênio dissolvido e temperatura da água também podem agir com estímulo à efetivação da desova em peixes. Nakatani et al. (1993), no reservatório de Itaipu, observaram maiores densidades larvais de Plagioscion squamosissimus (Heckel, 1840) em momentos de elevados valores de temperatura da água e após grandes variações de declínio e elevação nos valores $\mathrm{pH}$ e condutividade elétrica. Entretanto, Oliveira \& Araujo Lima (1998) não encontraram correlação entre a densidade de larvas de $M$. aureum e $M$. duriventre $\mathrm{e}$ a temperatura e oxigênio dissolvido nos estratos de fundo e superfície dos diferentes habitats das margens do rio Solimões/Amazonas. Apesar da ausência de informações sobre a relação entre a desova dos peixes e as variações de $\mathrm{pH}$, oxigênio dissolvido, temperatura e condutividade elétrica durante a enchente do rio Amazonas, estes fatores parecem exercer papel secundário na efetivação das desovas que ocorrem no canal principal do rio, devido às suas condições estáveis de temperatura e oxigênio (Fisher, 1978; Forsberg et al., 1988). 
Em adição aos fatores ambientais analisados, Bye (1984) afirmou que a maioria das espécies analisadas indicam a existência de um marcante ritmo reprodutivo endógeno, e que provavelmente são hábeis para manter um ciclo sazonal de maturação sexual com um periodo de aproximadamente um ano sem iniciação ou sincronização com estímulos externos. Ao contrário, neste experimento, o efeito da enchente sugere uma sincronização desova/enchente ligada as vantagens adaptativas ocasionadas pelo aumento constante no nivel do rio, favorecendo a sobrevivência das larvas na fase da primeira alimentação exógena, e não simplesmente uma sincronização com o ritmo endógeno anual.

\section{Em experimentos de} piscicultura, espécimes adultos de Colossoma macropomum (Cuvier, 1818) desovaram espontaneamente na mesma época que desovariam na natureza, sem o artifício de preparados hormonais ou estímulos externos como o aumento no nivel do rio (Kossowski et al., 1986). No entanto, o ritmo fisiológico destas espécies pode estar ligado a diversos fatores ambientais, que agiram como um ajuste do ritmo endógeno para o periodo reprodutivo no decorrer da sua prévia história ambiental.

Com o cultivo continuo em cativeiros, estas espécies sujeitas a um novo ambiente poderiam alterar esse ajuste endógeno em função de outras influências ou limitações de espaço, e a longo prazo desovariam em periodos mais curtos e diferentes ou em épocas semelhantes as observadas no ambiente natural. Portanto, $M$. aureum e $M$. duriventre apresentaram no meio natural uma forte correlação da enchente do rio com o início do período reprodutivo, possibilitando a previsão do início e do final da deriva das larvas e, provavelmente deve ser regra, para a maioria das espécies de Characiformes da Amazônia.

\section{AGRADECIMENTOS}

$\mathrm{O}$ projeto foi parcialmente financiado pelo $\mathrm{CNPq}$, através dos projetos proc. $401054 / 92$ e proc. 522551/96-3 e pelo INPA, PPI 3270. Agradeço ao Dr. Carlos Araujo Lima pelo auxilio nas análises estatísticas e pelo material cedido para este trabalho.

\section{Bibliografia citada}

Araujo-Lima, C.A.R.M. 1994. Egg size and larval development in Central Amazon fish. Journal of Fish Biology, 44:371-389.

Araujo-Lima, C.A.R.M.; Kirovsky, A.L.; Marca, A.G. 1993. As larvas dos pacus, Mylossoma spp (Teleostei; Characidae), da Amazônia Central. Revista Brasileira de Biologia, 53:591-600.

Araujo-Lima, C.A.R.M.; Oliveira, E.C. 1998. Transport of larval fish in the Amazon. Journal of Fish Biology, 53 (Supplement A):297-306.

Batista, V.S. 1998. Distribuiçào, dinâmica da frota e dos recursos pesqueiros da Amazónia Central. Tese de Doutorado, Instituto Nacional de Pesquisas da Amazônia/Fundação Universidade do Amazonas, Manaus, Amazonas, 291 p.

Bayley, P.B. 1973. Studies on the migratory characin, Prochilodus platensis Holmberg, 
1889, (Pisces, Characoidei) in the River Pilcomayo, South America. Journal of Fish Biology, 5: 25-40.

Boehlert, G.W.; Mundy, B.C. 1988. Roles of Behavioral and Physical Factors in Larval and Juvenile Fish Recruitment to Estuarine Areas. American Fisheries Society Symposium, 3: 51-67.

Bye, V.J. 1984. The Role of Environmental Factors in Timing of Reproductive Cycles. In: Potts, G.W.(ed.). Fish Reprodution. Academic Press. London, p.188-205.

Fernandes, C.C. 1997. Lateral migrations of fishes in Amazon floodplains. Ecology of Freshwaters Fish, 6:36-44.

Fisher, T.R. 1978. Plâncton e produção primária em sistemas aquáticos da Amazônia Central. Acta Amazonica, 8:4355 .

Forsberg, B.R.; Devol, A.H.; Richey, J.E.; Martinelli, L. A.; Santos, H. 1988. Factors controlling nutrient concentrations in Amazon floodplain lakes. Limnology and Oceanography, 33:41-56.

Godoy, M.P. 1959. Age, growth, sexual maturity, behavior, migration, tagging and trasplantation of the curimbatá (Prochilodus scrofa Steindachner, 1881) of the Mogi Guassu River, São Paulo State, Brasil. Anais da Academia Brasileira de Ciências, 31:447-477.

Goulding, M. 1980. The Fishes and the Forest: Explorations in Amazonian Natural History. University of California Press, Los Angeles, USA. 200 p.

Ihering, R. von; Azevedo, P. 1934. Os curimatas dos açudes nordestinos (Prochilodus argenteus), Archivos do Instituto Biológico, 5:143-196.

Junk, W.J.; Soares, M.G.M.; Carvalho, F.M. 1983. Distribution of fish species in a lake of the Amazon river floodplain near Manaus (Lago Camaleào) with special reference to extreme oxygen conditions. Amazoniana, 7(4):397-431.

Kossowski, C.L. 1980. Ensayo de reproduccion inducida en palometa carachica Mylossoma duriventre (Cuvier)
1818 (Pisces, Cypriniformes) con el uso de gonadotropina corionica humana. Acta Cient. Venezolana, 31:444-448.

Kossowski, C.L.; Prada, N.; Bermudez, D.; Madrid, F. 1986. Reporte sobre reproduciones espontaneas en cautiveiro de cachama, Colossoma macropomum en la Estación de Piscicultura de la Universidad Centro Occidental Lisandro Alvarado (Pisces: Cypriniformes). Revista Latinoamericana de Aquacultura, 29: 4.

Lowe-McConnell, R.H. 1979. Ecological aspects of seasonality in fishes of tropical waters. Symposia Zoological Society of London, 44: 219-241.

Lowe-McConnell, R.H. 1987. Ecological Studies in Tropical Fish Communities. Cambridge University Press, Cambridge, UK. $382 \mathrm{p}$.

Machado-Allison, A.; Castillo, O. 1992. Estudios sobre la sistematica de la subfamilia Serrasalminae. IV. El genero Mylossoma - Bases para la revision del grupo en America del Sur. Acta Biologica Venezuelica, 13:1-34.

Matsuura, Y. 1977. O ciclo de vida da sardinha-verdadeira (Introdução à oceanografia pesqueira). Publicação Especial do Instituto Oceanográfico da USP, São Paulo, 4:1-46.

Merona, B; Bittencourt, M.M. 1988. A pesca na Amazônia através dos desembarques no mercado de Manaus: resultados preliminares. Memoria Sociedad de Ciencias Naturales La Salle, 48:433-453.

Nakatani, K.; Latini, J.D.; Baumgartner, G.; Baumgartner, M.S.T. 1993. Distribuição espacial e temporal das larvas de curvina Plagioscion squamosissimus (Heckel, 1840) (Osteichthyes, Sciaenidae), no reservatório de Itaipu. Revista Unimar, 15:191-209.

Nikolsky, G.V. 1978. The Ecology of Fishes. T.F.H. Publications, Neptune City, USA. 352 p.

Oliveira, E.C.; Araujo Lima, C.A.R.M. 1998. Distribuição das larvas de Mylossoma aureum e $M$. duriventre (Pisces: Serrasalmidae) nas margens do rio 
Solimões, AM. Revista Brasileira de Biologia, 58(3):349-358.

Petrere Jr., M. 1985. A pesca comercial no Rio Solimöes-Amazonas e seus afluentes: análise dos informes do pescado desembarcado no Mercado Municipal de Manaus (1976-1978). Ciência e Cultura, 37:1987-1999.

Ribeiro, M.C.L.B. 1983. As migrações dos jaraquis (Pisces, Prochilodontidae) no Rio Negro, Amazonas, Brasil. Dissertação de Mestrado. Instituto Nacional de Pesquisas da Amazônia/Fundação Universidade do Amazonas. Manaus, Amazonas. 192 p.

Schwassmann, H.O. 1978. Times of annual spawning and reproductive strategies in Amazonian fishes. In: Thorpe, J.E.(ed.). Rhythmic activity of fishes, Academic Press. London, p.187-200.

Vazzoler, A.E.A.M.; Menezes, N.A. 1992. Síntese de conhecimentos sobre o comportamento reprodutivo dos Characiformes da América do Sul (Teleostei, Ostariophysi). Revista Brasileira de Biologia, 52:627-640.

Welcomme, R.L., 1985, River Fisheries. FAO Fisheries Technical Paper, 262:1-330.

Werder, U. 1983. Age determination by scale analysis in juvenile matrinchã (Brycon cf. melanopterus) a tropical characin from central Amazon. Amazoniana, 7:445-504.

Werder, U.; Soares, M.G.M. 1984. Age determination by sclerite numbers, and scale variation in six fish species from the Central Amazon (Osteichthyes, Characoidei). Amazoniana, 8:395-420.

Wootton, R.J. 1990. Ecology of Teleost Fishes. Chapman and Hall, London, UK. 404 p.

Zar, J. H. 1984. Biostatistical analysis. PrenticeHall Inc., Englewood, UK. 620 p. 